\title{
Mensuração sérica de minerais e avaliação clínica de bovinos acometidos por "mal da ronca" na região norte do estado do Rio de Janeiro
}

\section{Minerals serum level and clinical evaluation of bovines suffering from "mal da ronca" in north region of Rio de Janeiro state}

\author{
Antonio Peixoto Albernaz, ${ }^{*}$ Cláudio Baptista de Carvalho, ${ }^{*}$ \\ José Renato Junqueira Borges, ${ }^{\star \star}$ Lério Gama Sales, ${ }^{*}$ Bianca Brand Ederli*
}

\begin{abstract}
Resumo
"Mal da ronca", "ronca", "roncadeira", "mal do roncado" ou "mal da ronqueira" é uma enfermidade de caráter crônico caracterizada por ruído respiratório audível à distância, que afeta bovinos azebuados, machos e fêmeas, com mais de 18 meses de idade. Os animais afetados vieram de regiões com concentração de água de chuva no terreno, onde o gado se alimentou se e bebeu dessa água. Alguns bovinos apresentaram deformação na região nasal, mais precisamente no chanfro. Devido à dificuldade de oxigenação e conseqüente incapacidade de locomoção e alimentação, evidenciou-se emagrecimento progressivo, culminando, em alguns casos, com morte. Foram avaliados os níveis séricos de cálcio, fósforo, magnésio, cloro e cobre em grupo sadio e doente, vindos da mesma região. Os animais doentes não demonstraram deficiência sérica dos elementos mensurados; entretanto, a diferença significativa observada entre os animais sadios e doentes sugeriu desequilíbrio mineral.
\end{abstract}

Palavras-chave: ronca, bovino, respiração, minerais.

\begin{abstract}
"Mal da ronca", "ronca", "roncadeira", "mal do roncado" or "mal da ronqueira", as called, is a chronicle pathological condition characterized by a respiratory noise audible from distance that affects zebu cattle of both sexes, with more than 18 months of age. Affected animals came from regions with rain water concentration in the ground, where the cattle fed and drunk water. Some animals showed a misshaping in the nasal region, more accurately in the chamfer. Besides poor oxygenation and consequently an inability to walk and feed, a progressive emaciation was observed, in some cases the anima:s dead. The calcium, phosphorus, magnesium, chloride and cupper serum level were evaluated in a health and a sick bovines group, came from the same region. Sick animals didn't show serum mineral deficiency, but, the significative difference between sick and health animals group suggested mineral desbalance.
\end{abstract}

Keywords: snore, cattle, respiration, minerals.

\section{Introdução}

Tokarnia et al. (1960) e Tokarnia e Dobereiner (1998) estudaram a afecção denominada vulgarmente de "ronca" e a definiram como doença caracterizada por apresentar respiração ruidosa, ocorrendo em bovinos na região do delta do rio Parnaíba nos estados do Piauí e Maranhão, também observada no Mato Grosso do Sul e Norte do estado do Rio de Janeiro, mais precisamente no município de Campos dos Goytacazes. Citaram ainda que os animais apresentavam-se subnutridos, com pêlos ásperos, muitas vezes escuros e alguns pareciam descorados, demonstravam-se facilmente excitáveis e tinham diarréia. Nos bovinos portadores da enfermidade que foram necropsiados, observou-se que ocorria hemossiderose hepática e baixa concentração de cobre no tecido hepático, concluindo-se que o mesmo apresentava-se deficiente.
Albernaz (1999) em observações realizadas na região Norte Fluminense, durante exame clínico de animais com "mal da ronca", denominação utilizada na região para a enfermidade "ronca", observou emagrecimento progressivo, alteração da estrutura anatômica da região nasal caracterizada por depressão na região do chanfro e estenose das vias aéreas, mais precisamente na região do septo nasal, presença de ruído inspiratório acompanhado de dificuldade respiratória em repouso, sendo sempre acentuada em esforço, podendo levar à morte por hipóxia tecidual.

Silveira (1999) estudou 11 bovinos (fêmeas) com "mal da ronca", adultos, mestiços e voltados para pecuária de corte, todos oriundos da região Norte Fluminense. Observou, após eutanásia, alterações macróscópicas nos septos nasais dos 11 animais, sendo caracterizadas por espessamento e de-

\footnotetext{
* Universidade Estadual do Norte Fluminense - UENF, Av. Alberto Lamego, 2000, CEP. 28015-620, Campos dos Goytacazes, RJ. E-mail: a.albernaz@uol.com.br

** Universidade Nacional de Brasília - UnB.
} 
formação local, com área amarelada e de consistência diminuída. A microscopia da cartilagem do septo nasal revelou, nos 11 animais, degeneração mucóide, mineralização (calcificação distrófica) e metaplasia óssea, caracterizando, desta forma, a condrodistrofia do septo nasal em bovinos do Norte Fluminense, como uma das causas da entidade "mal da ronca". O mesmo autor descreveu ainda que, em seis animais, foi observada hemossiderose hepática.

Objetiva-se definir a etiologia da enfermidade, tomando como base informações já existentes que sugerem disfunção mineral.

\section{Material e métodos}

Foram utilizados 58 bovinos divididos em dois grupos (29 animais em cada grupo), machos e fêmeas, azebuados, com idade variando entre 18 e 120 meses. O primeiro grupo foi denominado Grupo R, constituído de bovinos portadores do "mal da ronca", sendo quatro machos e 25 fêmeas. Desses 29 animais, dois animais tinham idade entre 18 e 24 meses, 27 tinham idade acima de 24 meses. Todos os animais eram portadores de ruído respiratório estenótico (ronco). $\mathrm{O}$ segundo grupo foi denominado Grupo $\mathrm{C}$, constituido de bovinos sadios, sendo 29 fêmeas. Desse total, um animal tinha idade entre 12 e 24 meses e 28 tinham idade acima de 24 meses. Os bovinos utilizados eram oriundos de 13 propriedades da região Norte do estado do Rio de Janeiro, mais precisamente da Baixada Campista (município de Campos dos Goytacazes) e do município de Quissamã, criados de forma extensiva e direcionados para pecuária de corte, recebendo suplementação mineral, segundo informações dos proprietários. O período de colheita de material ocorreu entre novembro de 1997 e julho de 1998.

Todos os animais foram contidos e examinados clinicamente, segundo critérios estabelecidos por Rosemberger (1983), utilizando-se inspeção, palpação, auscultação e percussão. Foram colhidos $10 \mathrm{ml}$ de sangue da veia jugular externa com aguIha hipodérmica em frascos sem anticoagulante, acondicionados em caixa isotérmica, mantidos sob refrigeração e transportados para o Laboratório de Sanidade Animal (LSA). Após retração do coágulo, as amostras foram centrifugadas a 1.500 rpm, obtendo-se amostras de soro que foram congeladas a $20^{\circ} \mathrm{C}$ para posterior análise química. Foram determinadas as concentrações de cálcio, cobre, cloretos, fósforo e magnésio.

$\mathrm{Na}$ análise de cobre, cloretos, fósforo e magnésio utilizou-se espectrofotômetro computadorizado e semi-automático (Microlab 200) produzido pela Merck S. $A^{1}$ e kits reagentes fabricados pela Analisa Diagnóstica ${ }^{2}$ e Merck S.A.

\footnotetext{
1 Merck S.A.. E. Merck, 64271 Darmstadt, Germany.

2 Analisa Diagnóstica, Av. Nossa Senhora de Fátima, 2343, $5^{\circ}$ andar, conjunto 501/502, Belo Horizonte, MG.
} mesma espécie
O aparelho foi previamente programado, seguindo o protocolo fornecido pelo fabricante dos kits reagentes. A dosagem de cálcio foi realizada em espectrofotômetro Baush \& Lomb modelo D20, utilizando-se kits reagentes fabricados pela Analisa Diagnóstica, no Laboratório de Patologia Clínica da Faculdade de Medicina Veterinária da Universidade Federal Fluminense (UFF). Os dados foram tabulados e analisados estatisticamente, utilizando-se análise descritiva e comparação de médias através do teste de Wilcoxon $(p \leq 0,05)$.

\section{Resultados}

No grupo $R$ (doentes), dos 29 animais observados, 25 eram fêmeas, o que corresponde a $86,2 \%$, e o restante, quatro animais machos, corresponderam a $13,8 \%$, do total. Os resultados obtidos na avaliação dos valores médios de ambos os grupos, comparando-se aos valores demonstrados por Kaneko (1989) estão descritos na Tabela 1. Na Tabela 2 são mostradas as médias, desvios-padrão e os resultados obtidos na comparação entre médias dos grupos $R$ e $C$, segundo o teste de Wilcoxon $(p \leq 0,05)$.

Tabela 1 - Comparação entre os valores médios obtidos na mensuração sérica de cálcio, cobre, cloretos, fósforo e magnésio em bovinos portadores do "mal da ronca" (grupo R), bovinos sadios (Grupo C), e os valores descritos por Kaneko (1989) para a

\begin{tabular}{lccccc}
\hline & $\begin{array}{c}\text { Cálcio } \\
(\mathrm{mg} / \mathrm{dl})\end{array}$ & $\begin{array}{c}\text { Cobre } \\
(\mu \mathrm{g} / \mathrm{dl})\end{array}$ & $\begin{array}{c}\text { Cloretos } \\
(\mathrm{mmol})\end{array}$ & $\begin{array}{c}\text { Fósforo } \\
(\mathrm{mg} / \mathrm{dl})\end{array}$ & $\begin{array}{c}\text { Magnésio } \\
(\mathrm{mg} / \mathrm{dl}\}\end{array}$ \\
\hline Grupo R & $14,04 \pm 7,64$ & $101,94 \pm 52,40$ & $94,61 \pm 12,87$ & $7,62 \pm 1,68$ & $2,13 \pm 0,34$ \\
Grupo C & $14,42 \pm 9,15$ & $182,61 \pm 76,30$ & $87,93 \pm 18,57$ & $5,88 \pm 2,63$ & $1,35 \pm 1,25$ \\
Kaneko (1989) & $11,05 \pm 1,35$ & $34,0 \pm 1,2$ & $104 \pm 7,0$ & $7,82 \pm 0,58$ & $2,05 \pm 0,25$ \\
\hline
\end{tabular}

Os resultados obtidos na comparação, através de análise estatística descritiva, entre os valores médios de cálcio, cloretos, fósforo e magnésio observados no Grupo R (doentes), no Grupo C (sadios) e os valores médios, referentes aos mesmos elementos, descritos por Kaneko (1989) demonstraram normalidade, entretanto, os valores médios de cobre apresentaram-se, em ambos os grupos, acima dos citados por Kaneko (1989).

Tabela 2 - Médias e desvios padrão referentes à mensuração sérica de cálcio, cobre, cloretos, fósforo e magnésio em bovinos portadores do "Mal da Ronca" (grupo R) e bovinos sadios (grupo C), oriundos do Norte do estado do Rio de Janeiro e resultados da comparação de médias segundo Teste de Wilcoxon $((p \leq 0,05)$

\begin{tabular}{|c|c|c|}
\hline & $\begin{array}{c}\text { Média/Desvio-padrão } \\
\text { Grupo R }\end{array}$ & $\begin{array}{c}\text { Média/Desvio-padrão } \\
\text { Grupo C }\end{array}$ \\
\hline Cálcio $(\mathrm{mg} / \mathrm{dl})^{n \mathrm{~ns}}$ & $14,04 \pm 7,64$ & $14,42 \pm 9,15$ \\
\hline Cobre $(\mu \mathrm{g} / \mathrm{dl})^{*}$ & $101,94 \pm 52,40$ & $182,61 \pm 76,30$ \\
\hline Cloretos $(\mathrm{mmol} / \mathrm{L})^{\mathrm{ns}}$ & $94,61 \pm 12,87$ & $87,93 \pm 18,57$ \\
\hline Fósforo $(\mathrm{mg} / \mathrm{dl})^{*}$ & $7,62 \pm 1,68$ & $5,88 \pm 2,63$ \\
\hline Magnésio $(\mathrm{mg} / \mathrm{dl})$ * & $2,13 \pm 0,34$ & $1,35 \pm 1,25$ \\
\hline
\end{tabular}

* - significativo e ns - não-significativo segundo o teste de Wilcoxon $(p \leq 0,05)$. 
O teste de Wilcoxon $(p \leq 0,05)$, utilizado na comparação de médias, demonstrou diferença significativa entre os valores médios de cobre, fósforo e magnésio. No Grupo $R$ (doentes), os valores médios de cobre foram significativamente menores, enquanto os de fósforo e magnésio foram significativamente maiores.

$\mathrm{Na}$ avaliação clínica dos 29 animais observados, 1 animal apresentou respiração com ruído estenótico expiratório e 28 (vinte e oito) apresentavam respiração com ruído estenótico inspiratório que se acentuava quando de esforço. Do total de animais doentes, 12 apresentaram deformação côncava (depressão) na região do chanfro.

\section{Discussão}

A maior prevalência de fêmeas acometidas pelo "mal da ronca" pode ser explicada pelo fato das mesmas existirem em maior número no rebanho, visando fins reprodutivos. Contudo, a prevalência de bovinos azebuados pode ser explicada pelo fato dos mesmos serem predominantes na região, sendo criados de forma extensiva, visando a pecuária de corte. Constatou-se que os animais tinham acesso a áreas alagadas ("brejos") dentro das propriedades, alimentandose da água existente no local, que é considerada "ferruginosa". Desta forma, o terreno onde vivem esses animais, quando seco, apresentou características semelhantes às citadas por Tokarnia e Dobereiner (1998). Sobre o aspecto clínico, no grupo de 29 animais, 28 apresentaram respiração ruidosa inspiratória que, ao esforço, sofria intensificação. Apenas 1 animal apresentou respiração ruidosa expiratória. Dentre os 29 animais doentes, 12 apresentaram deformação na região do chanfro, caracterizando, desta forma, o comprometimento nasal citado por Silveira (1999). A deformação observada suscitou dificuldade de oxigenação e conseqüente incapacidade de locomoção e alimentação, evidenciando-se emagrecimento progressivo, culminando, em alguns animais, com morte. Em alguns casos, quando se retirava o animal dos locais alagadiços, o processo patológico parecia estacionar, embora em outros, tal medida não surtisse efeito e o óbito era inevitável. Na mensuração de minerais no soro dos animais, que, de acordo com Rosero (1990), além da mensuração realizada em ossos ou fígado, representa metodologia eficaz para a determinação de deficiências minerais, os valores médios de cálcio, fósforo, magnésio e cloro mostraram-se dentro da normalidade, com exceção do valor médio de cobre, que se mostrou acima da normalidade, quando comparado com o citado por Kaneko (1989). No entanto, o valor de cobre sérico diferiu do encontrado e citado por Tokarnia et al. (1960 e 1971) e Tokarnia e Dobereiner (1998). Acredita-se que tal discrepância de valores seja explicada pelo fato do elemento cobre não estar primariamente envolvido na etiologia da doença, aceitando-se a possibilidade de deficiência de cobre como fator secundário ao próprio estado de caquexia gerado por dificuldade de locomoção e alimentação apresentada pelos animais acometidos pelo "mal da ronca". Nesse aspecto há importante contribuição literária de Alves (2000), que ao analisar a composição mineral no solo, forragem e água em 16 propriedades onde ocorria o "mal da ronca" na região Norte Fluminense, constatou que os teores médios de cobre nas forrageiras foram considerados normais para a nutrição de bovinos na época seca e deficientes na época chuvosa. Há que se ressaltar que, no presente estudo, todos os proprietários questionados afirmaram realizar suplementação mineral rotineira. Lumsden (2000) ressaltou que, estatisticamente, para se trabalhar com mais segurança em relação aos resultados obtidos, é importante que sejam utilizados grupos de indivíduos de uma mesma região ou, no mínimo, demograficamente parecidas, com as mesmas características raciais, com sexo, idade e manejo compatíveis entre si. No entanto, a comparação dos valores médios obtidos no grupo estudado com os valores médios obtidos com animais estudados em outras regiões e citados na literatura também apresentam importância. No presente estudo, realizou-se a comparação dos resultados obtidos nos animais doentes estudados com um grupo de animais sadios da mesma região, com 29 animais fêmeas, com as mesmas características raciais e de manejo, seguindo o proposto por Lumsden (2000). Além disso, os resultados também foram comparados com os já existentes na literatura. Nessa análise, os valores médios de fósforo, magnésio e cobre apresentaram-se estatisticamente (segundo Teste de Wilcoxon, com $\mathrm{p} £ 0,05$ ) diferentes entre si, corroborando, desta forma, com o citado por autores como Tokarnia et al. (1960) e Tokarnia e Dobereiner (1998), isto é, a patologia "ronca" representa uma entidade patológica que envolve alteração mineral. Contudo, definir exatamente a fisiopatologia da referida doença é momentaneamente extremamente difícil, o que constitui um desafio nesta linha de investigação. É necessário enfatizar que a escassez de literatura específica constitui obstáculo evidente, o que torna imperiosa a necessidade de pesquisas contínuas.

\section{Conclusões}

De acordo com as observações realizadas, concluiu-se que:

1 Não ocorreu deficiência sérica de cálcio, fósforo, cobre, cloro e magnésio.

2 Os elevados valores médios de cobre em ambos os grupos e a diferença significativa existente entre os valores de fósforo, magnésio e cobre demonstraram desequilíbrio mineral.

3 Clinicamente, o "mal da ronca" carcteriza-se pelo aparecimento de ruído respiratório estenótico, acometendo bovinos machos e fêmeas a partir de 18 meses de idade.

\section{Agradecimentos}

À Prof.a. Nádia Regina Pereira Almosny, do Laboratório de Patologia Clínica da Faculdade de Medicina Veterinária da Universidade Federal Fluminense, pela valiosa contribuição na mensuração sérica de cálcio. 


\section{Referências}

ALBERNAZ, A. P. Aspectos clínicos e laboratoriais de bovinos com "mal da ronca" no norte fluminense. 1999. 82 p. Dissertação (Mestrado)-UENF, Campos dos Goytacazes.

ALVES, R. B. M. Composição mineral no solo, forragem e água em locais onde ocorre a Condrodistrofia do Septo Nasal ("Mal da Ronca") em bovinos na região Norte Fluminense. 2000. 134 p. Dissertação (Mestrado)-UENF, Campos dos Goytacazes.

KANEKO J. Clinical biochemistry of domestic animals. $4^{\text {th }} . e d .$, New York: Academic, 1989. $725 \mathrm{p}$.

LUMSDEN J. H. Reference vallues, In: FELDMAN, B. V.; ZINKL, J. G.; JAIN, N. C. Schalm's Veterinary Hematology. Canadá. Lippincott Willians \& Wilkins, 2000, 2. cap., p. 12-15.

ROSENBERGER, G. Exame clínico dos bovinos. Rio de Janeiro: Guanabara Koogan, 1983.
ROSERO O. Metodología de investigación en nutrición mineral de ruminantes. In: RUIZ, M. E.; RUIZ, A. Nutrición de ruminantes: guia metodológica de investigación. San José. Instituto Interamericano de Cooperación para la Agricultura: Red de Investigación en Sistemas de Producción Animal en Latinoamérica, 1990, 1. cap., p. 33-48.

SILVEIRA, L. S. Condrodistrofia do Septo Nasal (Mal da Ronca) em bovinos do Norte Fluminense. 1999, 25 p. Dissertação(Mestrado)UENF.

TOKARNIA, C. H.; CANELLA, C. F. C.; DOBEREINER J. Deficiência de cobre em bovinos no delta do rio Parnaíba, nos estados do Piauí e Maranhão. Rio de Janeiro. Arqs Inst Biol Animal, v. 3, p. 25-37, 1960.

TOKARNIA, C. H. ; GUIMARÃES, J. A. Canella; C. F. C. et al. Deficiências de cobre e cobalto em bovinos e ovinos em algumas regiões do Brasil. Rio de Janeiro. Pesq Agropec Bras, Sér Vet, v. 6, p. 61-77, 1971.

TOKARNIA, C. H.; DOBEREINER, J. Sobre o "ronca", doença de etiologia obscura em bovinos, caracterizada por respiração ruidosa. Rio de Janeiro. Pesq Vet Bras, v. 18, n. 3/4), p. 93-98, 1998. 